\title{
HIV associated thrombotic microangiopathy
}

\author{
S Ahmed, R K Siddiqui, A K Siddiqui, S A Zaidi, J Cervia
}

Postgrad Med J 2002;78:520-525

Thrombotic microangiopathy (TMA) is a known complication of HIV infection. Endothelial cell injury appears to be the primary event causing platelet activation and deposition in the microvasculature. Direct cytopathic roles of HIV as well as other factors such as malignancy, drugs, and infectious agents have been implicated in the pathogenesis of HIV-TMA. Although the the majority of patients present in a more advanced stage of HIV disease, TMA can be the initial presenting symptom of HIV infection. Clinical features are those of idiopathic TMA, and the diagnosis should be suspected in any patient with new onset thrombocytopenia and microangiopathic haemolytic anaemia. Therapy with plasma exchange or infusion appears to be efficacious. A rapid diagnosis and institution of plasmapheresis is crucial for a favourable outcome. The long term prognosis of HIV-TMA is unfavourable and may depend on the stage of HIV infection. The recent data after the use of highly active retroviral treatment, however, are unavailable and current prognosis is therefore uncertain.

See end of article for authors' affiliations

Dr Joseph Cervia, Division of Infectious Disease, Staff House, Suit 226, Long Island Jewish Medical Center, 270-05 76th Avenue, New Hyde Park NY 11040, USA cervia@lij.edu

Submitted 18 March 2002 Accepted 19 June 2002
$\mathrm{T}$ syndrome characterised by microangiopathic haemolytic anaemia, thrombocytopenia, microvascular thrombosis, and multisystem organ dysfunction..$^{1-3}$ Pathologically TMA is defined as a lesion of vascular wall thickening, intraluminal platelet thrombosis (hyaline thrombi), and vascular occlusion. ${ }^{1}$ The thrombotic lesions typically involve terminal arterioles and capillaries. Two pathologically indistinguishable but clinically distinct entities have been described, haemolytic uraemic syndrome (HUS) and thrombotic thrombocytopenic purpura (TTP).

TTP is a diffuse thrombotic microangiopathy which classically manifests with microangiopathic haemolytic anaemia, thrombocytopenia, renal dysfunction, neurological symptoms, and fever. A central nervous system microangiopathy that leads to the emergence of neurological symptoms constitutes an important component of the disorder. Without appropriate treatment, TTP is a fatal entity; but a marked improvement in the survival rate has been demonstrated when therapy with plasma exchange or plasma infusion is instituted promptly. ${ }^{4}$ HUS on the other hand, is a more localised form of thrombotic microangiopathy that is characterised by severe renal dysfunction with a paucity of neurological abnormalities. ${ }^{1-3}$ In practice, however, the differences between TTP and HUS are seldom clear cut, and symptoms may shift from one syndrome to hrombotic microangiopathy (TMA) is clinical another. Epidemic HUS in young children initiated by infections with shiga toxin-producing strains of shigella or Escherichia coli (typically E coli 0157:H7) appears to be distinct from all other forms of HUS in terms of prognosis and response to treatment. ${ }^{6-8}$

The pathophysiology of TMA is incompletely understood but injury to the endothelial cell is considered to be the central and likely inciting factor. The triggers of TMA include infections, drugs, collagen vascular disease, cancer, and pregnancy among others; however, often no triggering condition is apparent (box l). TMA is a rare but a well known complication of HIV infection. The association of TMA with HIV infection was first described in 1984. ' Subsequently TMA has been increasingly reported in HIV infected patients over the past decade. ${ }^{10-19}$ In the present review, we discuss the pathophysiology, clinical features, diagnosis, treatment, and prognosis of TMA in HIV infected patients.

\section{EPIDEMIOLOGY}

TMA occurs with an annual incidence of 3.7 cases per 100000 persons in the general population. ${ }^{20}$ It is slightly more common in females (female: male ratio $3: 2$ ) and has a peak incidence in the third decade. $^{21}{ }^{22}$ The incidence of TMA is found to be raised in patients with HIV infection compared with the general population, and a higher incidence is found in advanced HIV infection. ${ }^{10-192324}$ HIV infection was found in $14 \%-20 \%$ of patients presenting with TMA in a retrospective series, and the association has been confirmed in a case-control study. ${ }^{14}{ }^{16}$ Among patients with HIV-TMA, males are predominantly affected, and homosexual behaviour and intravenous drug abuse are identified as two major risk factors for their HIV infection. ${ }^{18}$

\section{AETIOLOGY AND PATHOGENESIS} Idiopathic TMA

Endothelial cell injury appears to be the primary event in the pathogenesis of TMA causing platelet activation and deposition in arterioles and capillaries. Potential factors that have been implicated in causing endothelial injury and activation are bacterial shiga toxin/endotoxin, viral infection, antibodies, and immune complexes and drugs among others. ${ }^{25-28}$ Evidence also indicates that the capacity of endothelial cells to inhibit platelet activation and mediate vasodilation through the elaboration of prostacyclin may be impaired. ${ }^{29}$

Abbreviations: HUS, haemolytic uraemic syndrome; TMA, thrombotic microangiopathy; TTP, thrombotic thrombocytopenic purpura 
Box 1: A classification of thrombotic microangiopathy

- Idiopathic thrombotic microangiopathy (TMA): with thrombotic thrombocytopenic purpura (TMA-TTP); with sporadic haemolytic uraemic syndrome (TMA-HUS)

- Familial TMA.

- Toxin associated TMA: childhood epidemic HUS; sporadic HUS.

- Drug associated TMA: quinine, ticlopidine, mitomycin C, cyclosporin.

- Transplant associated TMA.

- Malignancy associated TMA.

- Pregnancy associated TMA.

- Collagen vascular disease associated TMA.

- HIV associated TMA.

Loss of physiological thromboresistance, leucocyte adhesion to damaged endothelium, complement consumption, abnormal von Willebrand factor release and fragmentation, and increased vascular shear stress may then sustain and amplify the microangiopathic process.'

Endothelial cell injury may also promote platelet adhesion to the vasculature by disrupting the production or processing of von Willebrand factor. The unusually large multimers of von Willebrand factor are found in TMA patients, presumably after being released into the circulation from damaged endothelial cells. $^{30}{ }^{31}$ These ultralarge von Willebrand factor multimers could directly agglutinate platelets, especially when they are subjected to high shear stress. ${ }^{32}$ The partial arteriolar obstruction may result in a high shear stress in the vasculature of patients with TMA that could augment platelet reactivity with von Willebrand factor. ${ }^{33}$ Endothelial cell injury may promote platelet adhesion to the vasculature by disrupting the production or processing of von Willebrand factor. ${ }^{32}$ It has been reported that loss or dysfunction of the von Willebrand factor-cleaving protease is related to the development of acute or chronic TTP-HUS. ${ }^{34-36}$ The deficient plasma von Willebrand factor-cleaving metalloprotease activity may either be inherited as in patients with the familial or chronic relapsing form of TTP-HUS or acquired caused by autoantibody inhibition of protease activity. ${ }^{37}$ However, low plasma levels of the protease are not specific for TMA and low protease level is found in several other conditions as well. ${ }^{39}$

\section{HIV-TMA}

The mechanism involved in the pathogenesis of HIV related TMA remains speculative. Because the patients with HIV related TMA present at varied stages of HIV infection and with diverse infections and neoplasms, multiple factors can probably produce endothelial damage and/or platelet aggregation resulting in TMA. A direct cytopathic role of HIV by causing endothelial cell injury has been implicated in the pathogenesis of TMA. Other factors that may possibly be involved in HIV associated TMA include: drugs, malignancies, and direct vascular injury by infectious agents. ${ }^{16-18} \mathrm{~A}$ high prevalence of various malignancies has been noted in those patients who developed TMA. ${ }^{18}$ Likewise, in approximately one third of the reviewed cases of HIV-TMA, the syndrome was preceded by some infection. ${ }^{18}{ }^{40}$ An increased susceptibility to herpes, cytomegalovirus, and other infectious agents with endothelial tropism may be an inciting event in some cases of HIV-TMA. For example, cytomegalovirus has been shown to increase the procoagulant activity of endothelial cells, ${ }^{41}{ }^{42}$ and a high incidence of symptomatic cytomegalovirus infection was found in transplant related TMA. ${ }^{43}$ Drugs such as valacyclovir, fluconazole, and clofazamine have also been implicated in the pathogenesis of HIV-TMA. ${ }^{16}{ }^{44}$ However, the association between these drugs and TMA may be circumstantial as no cases of TMA were observed in 700 HIV infected patients treated with valacyclovir. ${ }^{45}$
Endothelial cell injury and activation are commonly observed in HIV infection. ${ }^{46}$ Endothelial activation in HIV infection may be mediated by direct viral invasion of endothelial cells, indirectly by the effect of secreted cytokines or by the action of HIV associated proteins such as Tat and gpl20 on endothelial cells. ${ }^{47-49}$ Both in vivo and in vitro studies demonstrated that endothelial cells are permissive to HIV infection in various tissues such as bone marrow, retina, brain, and glomeruli. ${ }^{50-53}$ Moreover, the presence of the HIV-1 p24 antigen in endothelial cells has been described in a patient with HIV related TMA. ${ }^{13}$ HIV infection of endothelial cells can occur both CD4 dependent or CD4 independent mechanisms. Some HIV-2 isolates have been described that use a chemokine receptor CXCR4 for virus entry in a CD-4 independent fashion. ${ }^{54}$ Expression of these chemokine receptors has been demonstrated on endothelial cells. ${ }^{556}$ This raises the possibility that HIV may be able to infect endothelial cells that express CXCR4 or perhaps other chemokine receptors. Various markers of endothelial cell damage such as von Willebrand factor, soluble thrombomodulin, adhesion molecule E-selectin, tissue type plasminogen activator, plasminogen activator inhibitor, fibronectin, angiotensin converting enzyme, and endothelin have been shown to be increased in the course of HIV infection. ${ }^{57-60}$ Similarly, various inflammatory cytokines such as tumour necrosis factor alpha and interlukin- 1 are found to be raised in HIV infected patients. ${ }^{61}$ These cytokines increased the expression of adhesion molecules on the endothelial cell surface and may be important in the pathway leading to endothelial damage. ${ }^{62}{ }^{63}$

A characteristic histological feature of TMA is the paucity of inflammation. ${ }^{1}$ Evidence supports enhanced apoptosis or programmed cell death of microvascular endothelial cells in patients with TMA.$^{64}$ Likewise, an increased endothelial cell apoptosis was also demonstrated in HIV infection. ${ }^{65}$ It has been also reported that plasma from patients with both idiopathic and HIV associated TMA can cause apoptosis of microvascular endothelial cells through a pathway involving induction of Fas (CD95). ${ }^{66}$ Various investigators have shown that endothelial cells acquire procoagulant properties upon activation of apoptosis. ${ }^{68-70}$ Hence, increased endothelial cell apoptosis may play a part in the pathogenesis of HIV-TMA. The role of the plasma von Willebrand factor-cleaving metalloprotease in the pathogenesis of HIV-TMA is uncertain because of the paucity of data about the protease level in HIV-TMA cases described in the literature.

\section{CLINICAL AND LABORATORY FEATURES}

The clinical spectrum varies from a low grade asymptomatic thrombocytopenia with mild renal insufficiency to a catastrophic illness with gross neurological deficits and renal failure requiring dialysis. In contrast to idiopathic TMA, many of the patients have coexisting AIDS defining illnesses such as Pneumocystis carinii pneumonia, Kaposi's sarcoma, cytomegalovirus colitis, or retinitis and cryptococcal meningitis. ${ }^{12-19}$ In a recent review of 93 cases of HIV associated TMA described in the literature, 32 patients had features of HUS and 61 patients were diagnosed with TTP. ${ }^{19}$ Of note, in $26(28 \%)$ cases TMA was the first clinical manifestation of HIV infection. While most patients had symptomatic HIV infection at the time of or soon after the diagnosis of TMA, asymptomatic or mild HIV infection (Centers for Disease Control stage I and II) was found in nearly one third of the patients. Patients affected by HUS presented in a more advanced stage of HIV disease and had a mean CD4 count of 70 cells/ $\mu$ l (20-400) compared with a mean CD4 count of $142(0-750)$ in patients with TTP.

Of note, patients with HIV related TTP seem to present with symptoms and signs quite similar to those of classic TTP. The classic pentad including neurological symptoms was noted in $36(60 \%)$ patients diagnosed with TTP. Additionally, in HIV related TTP central nervous system abnormalities were severe 


\section{Box 2: Laboratory features of HIV-TMA}

- Anaemia

- Thrombocytopenia.

- Presence of fragmented red blood cells or schistocytes.

- Raised serum indirect bilirubin and lactate dehydrogenase.

- Raised serum creatinine.

- Microscopic haematuria and proteinurea.

- Lack of laboratory evidence of coagulopathy.

with the frequent presence of seizure, coma, obtundation, and agitation. On the other hand, $22(68 \%)$ out of 32 patients diagnosed with HUS typically presented with haemolytic anaemia, thrombocytopenia, fever, and renal dysfunction. However, the neurological symptoms were noted only in one patient. Although renal involvement was commonly seen in HIV-TMA, it was often limited to haematuria and mild renal insufficiency in patients with TTP. By contrast, patients with HUS had more severe renal dysfunction and higher serum creatinine concentrations. Haemorrhagic diathesis was also seen in both groups, and 34\% patients with TTP and 16\% patients with HUS had a bleeding episode. ${ }^{19}$

Thrombocytopenia, microangiopathic haemolytic anaemia, and increased levels of serum lactate dehydrogenase were common laboratory findings. ${ }^{12}{ }^{19}$ Patients with TTP had a mean platelet count of $24.6 \times 10^{9} / 1$ (range 1-90) and those with HUS had count of $27.6 \times 10^{9} / 1$ (range $1-120$ ). The peripheral blood smear was used to support the diagnosis of TMA in most cases. The presence of fragmented red blood cells or schistocytes was the most widely reported abnormality on the smear. Bone marrow specimens were obtained in only a fraction of patients with the majority revealing erythroid hyperplasia. In two other small series of HIV-TMA, similar clinical and laboratory abnormalities were observed. ${ }^{15}{ }^{17} \mathrm{How}$ ever, in another series of 18 HIV related TMA, all patients had a gradual onset of disease in contrast to the sudden onset that is a characteristic of the classical syndrome. They also had less severe thrombocytopenia and less frequent neurological abnormalities. ${ }^{16}$

\section{DIAGNOSIS}

Thrombocytopenia is frequently seen in HIV infection. ${ }^{71-73}$ The reported incidence varies from $3 \%-8 \%$ of seropositive individuals to $30 \%-45 \%$ in patients with AIDS. ${ }^{74}{ }^{75}$ Likewise, other clinical features typical of TMA such as anaemia, neurological dysfunction, nephropathy, fever, and raised lactate dehydrogenase levels are also commonly seen in HIV infected patients due to various other causes. Hence, the initial diagnosis of TMA in HIV infected patients may be difficult. Recent studies, however, have required only the presence of microangiopathic haemolytic anaemia and thrombocytopenia without another clinically apparent cause to establish the diagnosis. ${ }^{51176}$ Examination of the peripheral blood smear, therefore, is essential in making the diagnosis. The diagnosis should be suspected in any patient with HIV infection who presents with a new onset thrombocytopenia and microangiopathic haemolytic anaemia. TMA can also mimic sepsis in HIV infected patients. However, while coagulation abnormalities are typically present in sepsis, they are uncommon in patients with TMA, and if present, usually are not severe. ${ }^{77}$

\section{TREATMENT}

The mainstay of treatment of HIV-TMA is plasma exchange, similar to that of idiopathic TMA. Treatment with antiretroviral agents may be an effective treatment for HIV-TMA as it can decrease HIV mediated endothelial damage. Use of antiretroviral agents in relapsing HIV-TMA has been associated with remission, and they should be considered in the chronic management of these patients. ${ }^{78}$

\section{Box 3: Differential diagnosis of TMA}

- Disseminated intravascular coagulation.

- Severe vasculitis.

- Sepsis (bacterial, viral, fungal, or rickettsial).

- Eclampsia.

- HELLP syndrome.

- Malignant hypertension.

- Catastrophic antiphospholipid syndrome.

\section{Plasma therapy}

To date a relatively small number of HIV-TMA cases have been reported, therefore, the precise role of plasma infusion and/or exchange as well as the long term outcome in these patients are not well known. However, based on the cases described in the literature, plasma therapy (fresh frozen plasma, cryodepleted plasma, or solvent detergent treated plasma), as either plasma infusion or exchange, appears to be an effective treatment in HIV-TMA. The superiority of plasma exchange over plasma infusion in idiopathic TMA was shown almost a decade ago, and this therapy should be considered as the standard treatment in patients with HIV-TMA as well. ${ }^{5}$ The effectiveness of plasmapheresis is thought to be the result of either removal of a harmful plasma component or the replacement of a deficient component.

Prompt response to the plasma exchange is evidenced by an increase in platelet count, improvement of anaemia, and normalisation of peripheral blood smear. Exchange should be performed daily with the goal of exchanging 1 to 1.5 times the plasma volume $(40-60 \mathrm{ml} / \mathrm{kg})$ with each procedure. Neurological improvement occurs most rapidly, often within hours to days. ${ }^{11}$ The serum lactate dehydrogenase level falls by $50 \%$ within three days in responders and platelet count begins to rise in a mean of five days, though normalisation may take several weeks. ${ }^{11}$ Impaired renal function is generally the last to improve. Plasma exchange should be continued until neurological symptoms have resolved, and both a normal serum lactate dehydrogenase and platelet count have been maintained for three days. A shorter duration of therapy risks immediate and occasionally fatal relapse.

Among 100 cases of HIV-TMA reported in the literature, plasma exchange and/or plasma infusion was used in 86 cases. A complete response to treatment was reported in 41 (41\%) cases. ${ }^{16}$ In a separate review of 28 of those 100 cases, $81 \%$ of the patients were treated with plasma exchange. Nineteen per cent only received infusion with fresh frozen plasma. ${ }^{18}$ Twenty five per cent of these patients who received plasma exchange died of their disease compared with 33\% patients who only received plasma infusion. However, in a series of 18 HIV-TMA patients, a low response to plasma therapy appropriate for TMA was seen. Fifteen of 18 patients received plasma therapy. Eight patients received plasma exchange along with plasma infusion, five patients only received plasma infusion, and none of them had a complete response. ${ }^{16}$ In a series of 14 patients with HIV-TMA, three of 14 patients died of progressive disease within the first 24 hours of diagnosis, but no patient died of progressive TMA after 48 hours of institution of plasma exchange in addition to other therapy. ${ }^{17}$ Hence, a rapid diagnosis and institution of plasmapheresis is crucial for a favourable outcome.

\section{Other therapies}

The precise role of corticosteroids, splenectomy, and antiplatelet agents in patients with HIV-TMA is unknown. In a review of 28 cases of HIV-TMA, 23 patients (74\%) received at least one form of additional treatment in addition to plasma therapy: prednisone (20 patients), antiplatelet agents such as aspirin and dipyrridamole (15 patients), vincristine (seven patients), and intravenous gammaglobulin (two patients). ${ }^{18}$ 


\section{Box 4: Management of HIV-TMA}

- Plasmapheresis and/or plasma infusion should be performed promptly.

- Use of corticosteroids should be individualised.

- Splenectomy should be reserved for those patients who are refractory to plasma therapy.

- Antiplatelet agents should be avoided as haemorrhagic diathesis commonly observed in HIV-TMA patients.

- Antiretroviral therapy is an important component of the management.

- Haemodialysis should be considered in patients with severe renal dysfunction.

However, the individual benefit of these modalities in achieving remission is not known. Corticosteroids have frequently been used in idiopathic TMA with variable response rate. ${ }^{479} \mathrm{In}$ general, they are of little benefit of their own, and routine use of corticosteroid should be avoided in patients with HIV-TMA who often present with advanced HIV infection. ${ }^{23}$ Splenectomy is mainly confined to refractory TMA cases. ${ }^{41180} \mathrm{~A}$ patient with HIV-TMA refractory to plasma exchange had a permanent remission of his TMA and a survival of 38 months after splenectomy ${ }^{17}$ Therefore, splenectomy may have a role in the management of those patients who are refractory to large volume plasma exchanges. Antiplatelet agents such as aspirin, dipyridamole, and sulfinpyrazone have not been convincingly shown to increase the response to plasma exchange and may promote bleeding in the setting of severe thrombocytopenia. $^{25}$ Hence their use as first line therapy cannot be recommended. Lastly, there are several anecdotal reports of success with multiple other treatments in TMA such as azathioprine, cyclophosphamide, cyclosporin, and intravenous gammaglobulin. However, the role of these agents in HIV-TMA patients who often have profound immunosuppression is unknown. ${ }^{43} 7677$

\section{Platelet transfusion}

Platelet transfusions have been reported to exacerbate TMA. Cases of TMA with acute deterioration and death have been reported after platelet transfusion. ${ }^{41}$ Therefore, all patients who are receiving platelet transfusion either because of bleeding or undergoing invasive procedures should be carefully monitored for signs and symptoms of clinical deterioration.

\section{PROGNOSIS AND SURVIVAL}

The relapse rate appears to be less frequent in HIV related TMA compared with idiopathic TMA; however, the overall prognosis is less favourable. ${ }^{18} 1978$ Among 61 reviewed cases of HIV associated TTP, 33 (51\%) patients achieved a complete response, four (6\%) patients had partial response (14), and 28 $(43 \%)$ patients died. On the other hand, of total 32 cases of HUS, $10(31 \%)$ patients achieved a complete response, two patients (6\%) had a partial response, and $20(63 \%)$ patients died of their disease. Thus, the prognosis appears to be worse in HUS patients. ${ }^{19}$ In one series of HIV-TMA, however, many patients survived for weeks or months without plasma therapy, in contrast to the nearly universal rapid mortality in untreated patients with classical TMA and some patients had spontaneous improvement without specific therapy. ${ }^{16}$

The long term prognosis of HIV-TMA probably depends on the stage of HIV infection. The mortality of patients with symptomatic HIV infection (Centers for Disease Control stage IV) is three times higher (39\%) than mortality of patients with asymptomatic HIV infection (Centers for Disease Control stages II and III, 13\%). ${ }^{18}$ In the vast majority of patients, life expectancy rarely exceeded one year after the diagnosis. Similarly, in another series of nine patients with
Box 5: Key messages

- Thrombotic microangiopathy (TMA) is a clinical syndrome associated with multiple inciting events and is increasingly seen in HIV infected patients.

- HIV infection both directly and indirectly, by predisposing to malignancy, opportunistic infection, and exposure to various drugs has been implicated in the pathogenesis of HIV-TMA.

- Endothelial cell injury appears to be the primary event leading to platelet aggregation.

- Early diagnosis may be difficult as other clinical features typical of TMA such as anaemia, thrombocytopenia, neurological dysfunction, nephropathy, fever, and raised lactate dehydrogenase levels are also commonly seen in HIV infected patients due to various other causes.

- The diagnosis should be suspected in any HIV infected patient with new onset thrombocytopenia and microangiopathic haemolytic anaemia.

- TMA can be the initial presenting symptom of HIV infection and HIV testing may be considered in patients presenting with TMA.

- Plasma therapy (plasma exchange and/or infusion) appears to be efficacious and a rapid institution of therapy is crucial for a favourable outcome.

- The overall prognosis is less favorable for HIV-TMA than for idiopathic TMA and appears to be related to profound immunodeficiency.

- The recent data after the use highly active retroviral treatment is unavailable and current prognosis is therefore uncertain

HIV-TMA, seven patients died of TMA with or without sepsis within three months. Among these nine patients, eight belonged to Centers for Disease Control group IV..$^{15}$ This indicates that the poor prognosis in HIV-TMA is likely related to severe immunodeficiency. Most of the literature in HIV-TMA was written before the availability of effective antiretroviral therapy. In the past decade, however, the advent of highly active antiretroviral therapy has dramatically improved the overall prognosis of HIV infected patients. ${ }^{82}$ This improved prognosis has been associated with a significant reduction in various AIDS associated complications. At the present time it is not known whether this decline in morbidity and mortality among HIV infected patients with advanced immune depletion would also translate into an improvement in the prognosis of HIV-TMA. Future investigation is warranted to address this issue.

Authors' affiliations

S Ahmed, Division of Hematology and Oncology, Department of Medicine, Long Island Jewish Medical Center, New Hyde Park, NY, the Long Island Campus for the Albert Einstein College of Medicine, Bronx, New York

A K Siddiqui, Division of Pulmonary and Critical Care Medicine

S A Zaidi, J Cervia, Division of Infectious Diseases

R K Siddiqui, Department of Pathology, St Luke's Roosevelt Hospital, New York

\section{REFERENCES}

1 Ruggenenti $P$, Noris $M$, Remuzzi $G$. Thrombotic microangiopathy, hemolytic uremic syndrome, and thrombotic thrombocytopenic purpura. Kidney Int 2001;60:831-46.

2 Ruggenenti P, Remuzzi G. The pathophysiology and management of thrombotic thrombocytopenic purpura. Eur I Haematol 1996:56:191-7.

3 Kwaan HC, Soff GA. Management of thrombotic thrombocytopenic purpura and hemolytic uremic syndrome. Semin Hematol 1997;34:159-66.

4 Bell WR, Braine HG, Ness PM, et al. Improved survival in thrombotic thrombocytopenic purpura-hemolytic uremic syndrome. Clinical experience in 108 patients. N Engl J Med 1991;325:398-403. 
5 Rock GA, Shumak KH, Buskard NA, et al. Comparison of plasma exchange with plasma infusion in the treatment of thrombotic thrombocytopenic purpura. Canadian Apheresis Study Group. N Engl J Med 1991;325:393-7

6 Boyce TG, Swerdlow DL, Griffin PM. Escherichia coli 157:H7 and the hemolytic-uremic syndrome. N Engl J Med 1995;333:364-8.

7 Arbus GS. Association of verotoxin-producing $E$ coli and verotoxin with hemolytic uremic syndrome. Kidney Int 1997;51:91-6.

8 George JN. How I treat patients with thrombotic thrombocytopenic purpura-hemolytic uremic syndrome. Blood 2000;96:1223-9.

9 Boccia RV, Gelmann EP, Baker CC, et al. A hemolytic uremic syndrome with acquired immunodeficiency syndrome. Ann Intern Med 1984;101:716-17.

10 Leaf AN, Laubenstein $\mathrm{W}$, Raphael B, et al. Thrombotic thrombocytopenic purpura associated with human immunodeficiency virus type 1 (HIV 1) infection. Ann Intern Med 1988:109:194-7.

11 Thompson CE, Damon LE, Ries CA, et al. Thrombotic microangiopathies in the 1980s: clinical features, response to treatment, and the impact of the human deficiency virus epidemic. Blood 1992;80:1890-5.

12 Rarick MU, Espina B, Mocharnuk R, et al. Thrombotic thrombocytopenic purpura in patients with human immunodeficiency virus infection: a report of three cases and review of the literature. Am J Hematol 1992:40:103-9.

13 del Arco A, Martinez MA, Pena JM, et al. Thrombotic thrombocytopenic purpura associated with human immunodeficiency virus infection: demonstration of p24 antigen in endothelial cells. Clin Infect Dis 1993;17:360-3

14 Ucar A, Fernandez HF, Byrnes JJ, et al. Thrombotic microangiopathy and retroviral infections. A 13 year experience. Am J Hematol 1994;45:304-9.

15 Bachmeyer C, Blanche P, Sereni D, et al. Thrombotic thrombocytopenic purpura and hemolytic uremic syndrome in HIV-infected patients. AIDS 1995:9:532-3

16 Bell WR, Chulay JD, Feinberg JE. Manifestations resembeling thrombotic microangiopathy in patients with advanced human immunodeficiency virus (HIV) disease in a cytomegalovirus prophylaxis trial (ACTG 204) Medicine 1997;76:369-80.

17 Hymes KB, Karpatkin S. Human immunodeficiency virus infection and thrombotic microangiopathy. Semin Hematol 1997;34:1 17-25.

18 de Man AM, Smulders YM, Roozendaal KJ, et al. HIV-related thrombotic thrombocytopenic purpura: report of two cases and a review of literature. Neth J Med 1997;51:103-9.

19 Sutor GC, Schmidt RE, Albrecht H. Thrombotic microangiopathies and HIV infection: report of two typical cases, features of HUS and TTP, and review of literature. Infection 1999;27:12-15

20 Torok TJ, Holman RC, Chorba TL. Increasing mortality from thrombotic thrombocytopenic purpura in the United States. Analysis of national mortality data, 1968-1991. Am J Hematol 1995;50:84-90.

21 Cuttner J. Thrombotic thrombocytopenic purpura: a ten year experience. Blood 1908;56:302

22 Petitt RM. Thrombotic thrombocytopenic purpura: a thirty year review. Semin Thromb Hemost 1980;6:350-5

23 Ripamonti D, Gregis G, Casari S, et al. Prevalenvce of thrombotic microangiopathy in a cohort of HIV-infected patients. AIDS 1996;1286a.

24 Gervasoni C, Ridolfo AL, Binl T, et al. Thrombotic thrombocytopenic purpura and hemolytic uremic syndrome in HIV-infected patients. AIDS $1996 ; 1299 a$.

25 Andreolli SP. The pathophysiology of the hemolytic uremic syndrome. Curr Opin Nephrol Hypertens 1999:8:459-64.

26 Leung YD, Moake JL, Havens pl, et al. Lytic anti-endothelial cell antibodies in hemolytic-uremic syndrome. Lancet 1988;ii:183-6.

27 Remuzzi G, Bertani T. Renal vascular and thrombotic effects of cyclosporine. Am J Kidney Dis 1989;13:261-72.

28 Bennett CL, Weinberg PD, Rozenberg-Ben-Dror K, et al. Thrombotic thrombocytopenic purpura associated with ticlopidine. A review of 60 cases. Ann Intern Med 1998;1 28:541-4.

29 Remuzzi G, Zoja C, Rossi EC. Prostacyclin in thrombotic microangiopathy. Semin Hematol 1987;24:110-18.

30 Moake JL, Rudy CK, Troll JH, et al. Unusually large plasma factor VII: von Willebrand factor multimers in chronic relapsing thrombotic thrombocytopenic purpura. N Engl J Med 1982;307:1432-5.

31 Asada Y, Sumiyoshi A, Hayashi T, et al. Immunohistochemistry of vascular lesions in thrombotic thrombocytopenic purpura, with specia reference to factor VIII related antigen. Thromb Res 1985;38:469-79.

32 Moake JL. Studies on the pathophsiology of thrombotic thrombocytopenic purpura. Semin Hematol 1997;34:83-9.

33 Kroll MH, Hellums JD, McIntireLV, et al. Platelets and shear stress. Blood 1996;88: 1525-41

34 Tsai HM, Chun-Yet Lian E. Antibodies to von Willebrand factor-cleaving protease in acute thrombotic thrombocytopenic purpura. N Engl J Med 1998;339: 1585-94

35 Furlan M, Robles R, Galbusera M, et al. Von Willebrand factor-cleaving protease in thrombotic thrombocytopenic purpura and the hemolytic-uremic syndrome. N Engl J Med 1998;339:1578-84.

36 Veyradier A, Obert B, Houllier A, et al. Specific von Willebrand factor-cleaving protease in thrombotic microangiopathies: a study of 111 cases. Blood 2001;98:1765-72

37 Furlan $M$, Robles R, Solenthaler $M$, et al. Deficient activity of von Willebrand factor-cleaving protease in chronic relapsing thrombotic thrombocytopenic purpura. Blood 1997;89:3097-103.

38 Furlan M, Robles R, Solenthaler M, et al. Acquired deficiency of von Willebrand factor-cleaving protease in a patient with thrombotic thrombocytopenic purpura. Blood 1998;91:2839-46.
39 Mannucci PM, Canciani MT, Froza I, et al. Change in health and disease of the metlloprotease that cleaves von Willebrand factor. Blood $2001 ; 98: 2728-33$

40 Veenstra J, van der Lelie J, Mulder JW, et al. Low-grade thrombotic thrombocytopenic purpura associated with HIV-1 infection. Br J Haematol 1993:83:346-7.

41 Van Dam-Mieras MC, Bruggemann CA, Muller AD, et al. Induction of endothelial cell procoagulant activity by cytomegalovirus infection. Thrombosis Res Suppl 1987;47:69-75.

42 Haagmans BL, Stals FS, van der Meide PH, et al. Tumor necrosis factor alpha promotes replication and pathogenicity of rat cytomegalovirus. The procoagulant response of cytomegalo virus infected endothelial cells. J Virol 1994:68:364-70.

43 Hochstetler LA, Flanigan M, Larger DJ. Transplant-associated thrombotic microangiopathy: the role of $\lg G$ administration as initial therapy. Am J Kidney Dis 1994;23:444-50.

44 Rivaud E, Massiani MA, Vincent F, et al. Valacyclovir hydrochloride therapy and thrombotic thrombocytopenic purpura in a HIV-infected patient. Arch Intern Med 2000;160:1705-6.

45 Chulay JD, Bell AR. Long-term safety of valacyclovir for suppression of herpes simplex virus infection. Clin Infect Dis 1996;23:879.

46 Chi D, Henry J, Kelley J, et al. The effects of HIV infection on endothelial function. Endothelium 2000;7:223-42.

47 Mitola S, Soldi R, Zanon I, et al. Identification of specific molecular sturtures of human immunodeficiency virus type 1 Tat relavant for it biological effects on vascular endothelial cells. J Virol 2000;74:344-53.

48 Zidovetzki R, Wang JL, Chen P, et al. Human immunodeficiency virus Tat protein induces interlukin $6 \mathrm{~m}$ RNA expression in human brain endothelial cells via protein kinase C-and cAMP-dependent protein kinase pathways. AIDS Res Hum Retroviruses 1998;14:825-33.

49 Annuziata P, Cioni C, Toncatto S, et al. HIV-1 gpl 20 increases the permeability of rat brain endothelium cultures by a mechanism involving substance P. AIDS 1998;1 2:2377-85.

50 Moses AV, Williams SE, Heneveld ML, et al. Human immunodeficiency virus infection of bone marrow endothelium reduces induction of stromal hematopoietic growth factors. Blood 1996;87:919-25.

51 Bagasra O, Lavi E, Bobroski L, et al. Cellular reservoirs of HIV-1 in the central nervous system of infected individual: identification by the combination of in situ polymerase chain reaction and immunohistochemistry. AIDS 1996;10:573-85.

52 Skolnik PR, Pomcrantz RJ, de la Monte SM, et al. Dual infection of retina with human immunodeficiency virus type 1 and cytomegalovirus. Am J Ophthalmol 1989;107:361-72.

53 Green DF, Resnick L, Bourgoignic JJ. HIV infects glomerular endothelial and mesangial but not epithelial cells in vitro. Kidney Int 1992:41:956-60.

54 Endres MJ, Clapham PR, Marsh M, et al. CD4-independent infection by HIV-2 is mediated by fusin/CXCR4. Cell 1996;87:745-56.

55 Gupta SK, Lysko PG, Pillarisetti K, et al. Chemokine receptors in human endothelial cells. Functional expression of CXCR4 and its transcriptional regulation by inflammatory cytokines. J Biol Chem 1998;273:4282-7.

56 Volin MV, Joseph L, Shockley MS, et al. Chemokine receptor CXCR4 expression in endothelium. Biochem Biophys Res Commun 1998;242:46-53

57 Lafevillade A, Alessi MC, Poizot-Martin L, et al. Endothelial cell dysfunction in HIV infection. J Acquir Immune Defic Syndr 1992:5:127-31.

58 Seigneur M, Constans J, Blanu A, et al. Soluble adhesion molecules and endothelial damage in HIV infected patients. Thromb Haemost 1997:77:646-9.

59 Constans J, Guerin V, Couchouron A, et al. Autoantibodies directed against phospholipids or human beta 2-glycoprotein I in HIV-seropositive patients: relationship with endothelial activation and antimalonic dialdehyde antibodies. Eur J Clin Invest 1998;28:115-22.

60 Schved JF, Gris JC, Amaud A, et al. Von Willebrand factor antigen, tissue-typeplasminogen activator antigen, and risk of death in human immunodeficiency virus 1-related clinical disease: independent prognostic relevance of tissue-type plasminogen activator. J Lab Clin Med 1992;120:411-19.

61 Vyakarnam A, Meatar P, Meager A, et al. Altered production of tumor necrosis factor alpha and beta and interferon gamma by HIV-infected individuals. Clin Exp Immunol 1991;84: 109-15.

62 Karmann K, Hughes CC, Schechner J, et al. CD40 on human endothelial cells. Inducibilty by cytokines and functional regulation of adhesion molecule expression. Proc Nat Acad Sci U S A 1995:92:4342-6.

63 Cllins T, Read MA, Neish AS, et al. Transcriptional regulation of endothelial cell adhesion molecules. NF-kappa B and cytokines-inducible enhancers. FASEB J 1995;9:899-909.

64 Dang CT, Magid MS, Weksler B, et al. Enhanced endothelial cell apoptosis in splenic tissue of patients with thrombotic thrombocytopenic purpura. Blood 1999:93:1264-70.

65 Shi B, De Girolami U, He J, et al. Apoptosis induced by HIV-1 infection of the central nervous system. J Clin Invest 1996;98:1979-90.

66 Mitra D, Jaffe EA, Weksler B, et al. Thrombotic thrombocytopenic purpura and sporadic hemolytic-uremic syndrome plasma induce apoptosis in restricted lineage of human microvascular endothelial cells. Blood 1997;89:1224-34.

67 Laurence J, Mitra D. Apoptosis of microvascular endothelial cells in the pathophysiology of thrombotic thrombocytopenic purpura/sporadic hemolytic uremic syndrome. Semin Hematol 1997;34:98-105.

68 Bombeli T, Scwartz BR, Harlan JM. Endothelial cells undergoing apoptosis become proadhesive for nonactivated platelets. Blood 1999;93:3831-8. 
69 Bombeli T, Karsan A, Tait JF, et al. Apoptotic vascular endothelial cells become procoagulant. Blood 1997:89:29-42.

70 Greeno EW, Bach RR, Moldow CF. Apoptosis is associated with increased cell surface tissue factor procoagulant activity. Lab Invest 1996:75:281-9.

71 Ratner L. Human immunodeficiency virus-associated autoimmune thrombocytopenic purpura. A review. Am J Med 1989;86:194-8.

72 Walsh CM, Karpatkin S. Thrombocytopenia and human immunodeficiency virus-1 infection. Semin Oncol 1990;17:367-74.

73 Glatt AE, Anand A. Thrombocytopenia in patients infected with human immunodeficiency virus: treatment update. Clin Infect Dis 1995;21:415-23.

74 Zon LI, Groopman JE. Hematologic manifestations of the human immune deficiency virus (HIV). Semin Hematol 1988;25:208-18.

75 Mienties GHC, van Amerijden EJC, Mulder JW, et al. Prevalence of thrombocytopenia in HIV-infected and non-HIV infected drug users and homosexual men. Br J Haematol 1992;82:615-9.

76 George JN, Gilcher RO, Smith JW. Thrombotic thrombocytopenic purpura-hemolytic uremic syndrome: diagnosis and management. J Clin Apheresis 1998;13:120-5.
77 Rizvi MA, Vesely SK, George JN. Plasma exchange complication: a review of 59 consecutive thombotic thrombocytopenic purpura-hemolytic uremic syndrome (TTP-HUS) patients. Thromb Haemost 1999; 1066a.

78 Salem G, Terebelo H, Raman S. Human immunodeficiency virus associated with thrombotic thrombocytopenic purpura: successful treatment with zidovudine. South Med J 1991;84:493-5.

79 Bukowski RM, Hewlett JS, Reimer RR, et al. Therapy of thrombotic thrombocytopenic purpura: an overview. Semin Thromb Hemost 1981;7:1-8.

80 Winslow GA, Nelson EW. Thrombotic thrombocytopenic purpura. Indications for and results of splenectomy. Am J Surgery 1995; 170:558-61.

81 Gordon LI, Kwaan HC, Rossi EC. Deleterious effects of platelet transfusions and recovery thrombocytosis in patients with thrombotic microangiopathy. Semin Hematol 1987;24:194-201.

82 Palella FJ Jr, Delaney KM, Moorman AC, et al. Declining morbidity and mortality among patients with advanced human immunodeficiency virus infection. HIV Outpatient Study Investigatiors. N Engl J Med 1998;338:853-60.

\section{BENCH>PRESS}

\section{New PMJ online submission and review system}

am pleased to inform authors and reviewers of Postgraduate Medical Journal's new online submission and

review system. Bench $>$ Press is a fully integrated electronic system which uses the internet to allow rapid

and efficient submission of manuscripts, and the entire peer review process to be conducted online.

Authors can submit their manuscript in any standard word processing software. Graphic formats acceptable are: .jpeg, .tiff, .gif, and .eps. Text and graphic files are automatically converted to PDF for ease of distribution and reviewing purposes. Authors are asked to approve their submission before it formally enters the reviewing process.

To access the system click on "SUBMITTING YOUR MANUSCRIPT" on the PMJ homepage: http://www.postgradmedj.com/ or you can access Bench>Press directly at http://submitpmj.bmjjournals.com/.

We are very excited with this new development and we would encourage authors and reviewers to use the online system where possible. It really is simple to use and should be a big improvement on the current peer review process. Full instructions can be found on Bench $>$ Press and PMJ online. Please contact Natalie Davies, Project Manager, ndavies@bmjgroup.com for further information.

\section{Pre-register with the system}

We would be grateful if all PMJ authors and reviewers pre-registered with the system. This will give you the opportunity to update your contact and expertise data, allowing us to provide you with a more efficient service.

\section{Instructions for registering}

1. Enter http://submit-pmj.bmjjournals.com.

2. Click on "Create a new account" in the upper left hand side of the Bench>Press

homepage.

3. Enter your email address in the space provided.

4. Choose a password for yourself and enter it in the spaces provided.

5. Complete the question of your choice to be used in the event you cannot remember

your password at a later time (this will be needed if you forget your password).

6. Click on the "Complete step l" button at the bottom of the screen.

7. Check the email account you registered under. An email will be sent to you with

a verification number and URL.

8. Once you receive the email, copy the verification number and click on the URL hyperlink. Enter the verification number in the relevant field. Click on "Verify $m^{\prime \prime}$. This is for security reasons and to check that your account is not being used fraudulently.

9 . Enter/amend your contact information, and update your expertise data. 